\title{
Optimization of technology of special-purpose mineral wool products
}

\author{
Aleksey Zhukov ${ }^{1}$, Igor Bessonov ${ }^{2}$, Ekaterina Bobrova ${ }^{3}$, Andrey Medvedev ${ }^{1,}$, and Ekaterina \\ Zinovieva $^{1}$ \\ ${ }^{1}$ Moscow State University of Civil Engineering, 129337, 26, Yaroslavskoe shosse, Moscow, Russia \\ ${ }^{2}$ Research Institute of Building Physics of the Russian Academy of Architecture and Building, \\ 127238, Lokomotivny pr. 21, Moscow, Russia \\ ${ }^{3}$ Higher School of Economics University, 101000, 20 Myasnitskaya Ulitsa, Moscow, Russia
}

\begin{abstract}
Insulation systems must have a number of special properties when used on construction sites located in the zone of significant negative temperatures, wind load, and associated air filtration through building structures, under the influence of the coastal environment that forms salts on technical facilities associated with the production and transportation of petroleum products. Firstly, high operational stability, including under the influence of aggressive environments. Secondly, they must be non-flammable and have significant fire resistance limits. Thirdly, do not contain components that are toxic during normal operation or are released in the event of a fire. The analysis of possibilities has shown that products based on stone wool meet these requirements to the greatest extent as a thermal insulation material. The research presented in the article is based on a hypothesis about the use of products based on stone wool and epoxy binder on latent hardeners, which will allow us to obtain an energy-efficient material that fully meets the conditions of polar construction. The purpose of the research was to develop a method for selecting the parameters of manufacturing mineral wool products that affect the properties of mineral wool slabs to the greatest extent and to optimize the temperature of heat treatment of mineral wool carpet. Research methodology set out in the article is based on the method of mathematical planning of experiment and statistical processing of the results, followed by analytical optimization.
\end{abstract}

\section{Introduction}

About a 20 percent of the territory of Russian Federation is located in the Arctic, there resides about 1.5 million people and is located about 30 large and medium cities. Another significant factor is the concentration of a large number of exploited and unexploited economic deposits of natural resources (oil and gas among them) on the territories north of the 67 th parallel. In connection with the extraction and processing of natural resources necessary

\footnotetext{
*Corresponding author: medvedev747@yandex.ru
} 
to develop construction technologies in extremely low natural temperatures and permafrost [1-3].

Construction in these areas has become one of the priorities of modern technological development, which include the establishment of special construction systems, focused on the construction of high-risk facilities in the Arctic Circle. These objects include marine tankers, oil and gas platforms, equipment for the transport of oil, gas reducing installation and installation of oil refining. In each of the above objects, you must choose the right thermal insulation, which will provide a high thermal insulation capacity, and be fire-resistant and durable [4-6].

The development of mining natural resources occurs in all countries that have territories beyond the Arctic circle. Considerable experience has been gained by the British, Canadian and Scandinavian companies. Especially in terms of offshore oil production zones and autonomous drilling platforms and in terms of transportation of these products in subzero temperatures and extreme weather conditions. It should be noted here that the main area, which are engineer's decisions are designed and used for is the North Sea [7-8].

For example, the Norwegian Troll oil platform.It is the highest in the history of mankind construction, which has been moved relative to its starting position, and it was towed at a distance of more than 200 kilometers in 1996 into the North Sea, 80 kilometers north-west from Bergen at the south-west of Norway. The platform stands on the seabed at 303 meters below the sea surface; its height is 472 meters. In place of the Troll platform location is passes the Gulf Stream, which softens the climatic conditions.

The Russian experience in the construction and operation of oil and gas platforms inferior to foreign. The only platform that is producing petroleum products on the Russian Arctic shelf is the offshore ice-resistant stationary platform (MISP) "Prirazlomnaja". Production on this platform began in 2014 (Arctic oil varieties Arctic Oil (ARCO)), and the first million barrels of oil was produced September of the same year.The use of thermal insulation is necessary in terms of installation workability fire safety, comfort, and work to minimize the costs of all operations that accompany a technological process.

\section{Problem statement}

The use of thermal insulation materials is an effective method of forming an insulating shell, as well as reducing energy costs and increasing the durability of building structures. The properties and durability of products based on mineral wool is largely determined by the conditions of formation of the mineral wool mat, uniformityofdistribution and properly solidification of the binder inside the mat and the conditions of heat treatment [9-10].

From the standpoint of energy efficiency, functionality criterion of the construction system is the thermal resistance of the structure and the parameters determining the choice of thermal insulation material (TIM) is its thermal conductivity. From the viewpoint of service durability, the majorare strength properties. It is confirmed, including theoretically studies. The logic is as follow: reduction of strength characteristics leads to shrinkage (compaction) of the material, i.e. to increasing the average density and hence to an increase of the thermal conductivity and reducing the thermal resistance of the system.

Special requirements apply to structures and systems of insulation working in the extreme (cold or hot) climates. In hot climates, overheating of raw materials or petroleum products may result release of volatile that causes the increase of their content in the premises of the object in low-level sealing, as well as fraught with an explosion from any sparks. In cold weather conditions, thickening (jellification) of liquid hydro carbons is highly undesirable because it violates the pumping technology. In this case, it is recommended to use the heating system with thermal insulation [11-12]. 
Thermal insulation specialized structures (associated with production, processing and transportation of hydrocarbons) must comply with certain requirements. First, it's must be an effective as thermo-technical system, (adopted to ensure prescriptive to region thermal resistance of the insulating shell). Second, to be nonflammable and be able to withstand not only the estimated temperature of fire $\left(600^{\circ} \mathrm{C}\right)$, but also maintain its properties at temperatures of $1000-1200^{\circ} \mathrm{C}$ (these temperatures are created during combustion of oil in isolated or partially isolated premises). Third, the thermal insulation product must not contain components supporting the combustion or released during the combustion of toxic substances. Fourth, heat insulating materials must be energy efficient, i.e. the cost of the organization of insulation system (manufactured of thermal insulation, its installation and operation of the structures) must be paid off from their application within the prescribed period from 5 to 10 years [13-15].

These conditions are met by-products based on mineral fibers: basalt fiber and rock wool. Basalt fiber has a modulus of acidity up to 4.5 - more than that of rock wool, and therefore is more resistant to aggressive environments typical of the coastal climate, and showing its activity to a greater extent at positive temperatures. In the considered temperature range, it is sufficient to use fibers with an acidity modulus of 1.8-2, which is typical for stone wool fibers. The production of rock wool is more technological and less energy-intensive than the production of basalt fiber. On the other hand, when designing insulation systems for closed and confined spaces, the requirement for the use of non-toxic binders that have high adhesion to mineral fibers and do not reduce the operational stability of mineral wool products becomes relevant. A similar type is an epoxy binder on latent hardeners with a polycondensation temperature in the interval $90 \ldots 110$ oC [16-21].

\section{Results}

Most local technologies oriented to the production of mineral wool products dimensionaloriented structure, which is formed by special units: corrugator and spreader placed on the processing line. The properties of TIM made from mineral fiber are determined by a competent foundation of all stages of the process. Fiber properties (its strength parameters, elasticity, resistance to aggressive environment and so on.) are formed on the stages of preparation of the charge, its melting and processing into the fiber. The uniformity of distribution of the binder in the fibrous mat due to its type and condition of the introduction into the fiber medium. Properties of mineral wool mat determined by the conditions of formation of its structure, which, on the one hand should provide maximum fiber weaving, and the other - to ensure the preservation of the continuity of the mat. The final stage, which objective is to stabilize the mat structure and formation properties of the products is the heat treatment. This shows the importance of uniform solidification of the binder and the temperature range at which solidification occurs.

The objective of research was to optimize heat treatment process of the mineral wool mat, aimed at increasing the service durability of products and reducing energy costs for heat treatment.The following response functions are accepted: compressive strength of products at $10 \%$ deformation (Y1); average density of products (Y2); coefficient of thermal conductivity $(\mathrm{Y} 3=\lambda \times 1000)$.

It has been found that greatest impact on the experimental results (response function) the following factors had: the average density of the mineral wool carpet $\left(\mathrm{X}_{1}\right)$; the binder content $\left(\mathrm{X}_{2}\right)$; fiber diameter $\left(\mathrm{X}_{3}\right)$; fiber length $\left(\mathrm{X}_{4}\right)$; The temperature of heat treatment, ${ }^{\circ} \mathrm{C}\left(\mathrm{X}_{5}\right)$. The plan of the second phase of the experiment was constructed taking into account the areas of variation of these factors and in accordance with the conditions set out above. The experimental conditions are shown in table 1. 
Table 1. Conditions and results of the experiment

\begin{tabular}{|c|c|c|c|}
\hline Name of factor & $\begin{array}{c}\text { Symb } \\
\text { ol } \\
X_{i}\end{array}$ & $\begin{array}{l}\text { The mean } \\
\text { value of the } \\
\text { factor, } \overline{\mathrm{X}} i\end{array}$ & $\begin{array}{c}\text { Variationinte } \\
\text { rval, } \Delta \mathrm{X}_{\mathrm{i}}\end{array}$ \\
\hline 1 & 2 & 3 & 4 \\
\hline $\begin{array}{l}\text { The average density of mineral wool carpet, } \\
\kappa \Gamma / \mathrm{M}^{3}\end{array}$ & $\mathrm{X}_{1}$ & 50 & 20 \\
\hline Thebinder content, $\%$ & $\mathrm{X}_{2}$ & 3.5 & 1 \\
\hline Averagefiberdiameter, мкм & $X_{3}$ & 4 & 1.5 \\
\hline Averagefiberlength, Mм & $\mathrm{X}_{4}$ & 30 & 10 \\
\hline The temperature of heat treatment, ${ }^{\circ} \mathrm{C}$ & $\mathrm{X}_{5}$ & 100 & 10 \\
\hline
\end{tabular}

The object of the study was on precisely those factors which effect at the outcome are most. As a result, after the evaluation of the significance of the coefficients and check the adequacy of the models, the following regression equation:

$$
\mathrm{Y}_{1}=38+18 \mathrm{X}_{1}+6 \mathrm{X}_{2}+4 \mathrm{X}_{3}+7 \mathrm{X}_{4}+4 \mathrm{X}_{5}+2 \mathrm{X}_{1} \mathrm{X}_{4}+3 \mathrm{X}_{2} \mathrm{X}_{3}-3 \mathrm{X}_{5}^{2}
$$

If the confidence interval $\Delta b=1.6$

$$
\mathrm{Y}_{2}=96+36 \mathrm{X}_{1}-4 \mathrm{X}_{3}-9 \mathrm{X}_{4}-3 \mathrm{X}_{1} \mathrm{X}_{4}
$$

If the confidence interval $\Delta b=2.2$

$$
\mathrm{Y}_{3}=37.5+0.8 \mathrm{X}_{1}+0.3 \mathrm{X}_{3}+0.2 \mathrm{X}_{4}+0.1 \mathrm{X}_{1} \mathrm{X}_{3}
$$

If the confidence interval $\Delta b=0.08$

In the resulting experimental polynomials, some pair and square interactions appeared, which are important in predicting the properties of products (solving interpolation problems), their manufacturing parameters, and selecting optimization strategies. The strength of the mineral wool product is most influenced by the average density of the pressed mineral wool carpet and the length of the mineral fiber. There is two synergistic effect of increasing the strength of the combined influence of the average density of the carpet and the fiber diameter (due to the effect of the weave of the fibers in the carpet) and from the joint influence of the consumption of binder and the fiber diameter (due to the conditions of adhesion of the binder to the surface of the mineral fibers).

An increase in the heat treatment temperature within the range of variation leads to an increase in strength (up to a certain value), and when this value is exceeded, the strength begins to slowly decrease (the coefficients at X5 and at X52 are equal to 4 and -3 , respectively). This effect is determined by the conditions of solidification of the binder, which occurs in the temperature range of $104 \ldots 108$ oC. At high temperatures, the binder hardens and destructive processes begin to manifest themselves primarily at the contact boundaries of the solidified binder and the surfaces of the mineral fiber.

The average density of mineral wool slabs is most determined by the average density of the pressed miner-al wool carpet and the average length of the fibers. In this case, there is a synergistic effect of the density reduction due to the combined influence of the carpet density and fiber length, due to the higher elasticity of the fibers in the intertwined state.

The thermal conductivity of mineral wool products depends mostly on the average density of the mineral wool carpet and its diameter. The synergistic effect of their combined influence is determined by the conditions of conductive heat transfer (through a fiber matrix) and the convective component of heat transfer due to the high open porosity of the mineral wool carpet. 


\section{Discussion}

Analytical method of optimization of process parameters developed in MSCU and has been tested in the study of technology of structural materials for various applications. A special computer program GJ-STAT-06, allowing both to process the results of the experiment, and make analytical optimization of obtained polynomials.

Using the method of analytical local optimization developed at the NRU MGSU allows you to determine the optimal value of the heat treatment temperature. To obtain the values of the local optimum, the function $Y_{1}=f\left(X_{1}, X_{2}, X_{3}, X_{4}, X_{5}\right)$ is differentiated by $X_{5}$ and the resulting partial derivative is equal to 0 .The resulting encoded value $X_{5}=2 / 3$ is recalculated (using table 1) to the natural value, and we get the recommended heat treatment temperature of $107 \pm 1{ }^{\circ} \mathrm{C}$.

As a result of optimization of established a clear correlation between the average density of the panels and their thermal conductivity. Both of these, depending on the average density of the mat and are linear (Fig. 1). This feature has been taken into account in the formation of second nomogram sector where heat conduction of panels is determined by the relation between their average density and diameter of the mineral fibers. According of third sector nomogram is determined the dependence of strength panels at $10 \%$ deformation of the mat density and consumption of the binder.

Thus, with the help of the sectors of nomogram established correlation between the characteristics of the mat characteristic, fiber properties, consumption of binder, molding parameters and properties of the product. This nomogram allows us to solve a direct problem: predict the properties of the products depending on the setting value of variable factors and the inverse problem: to choose the ratio of the parameters characterizing the process to meet the requirements established for products for strength, density, thermal conductivity.

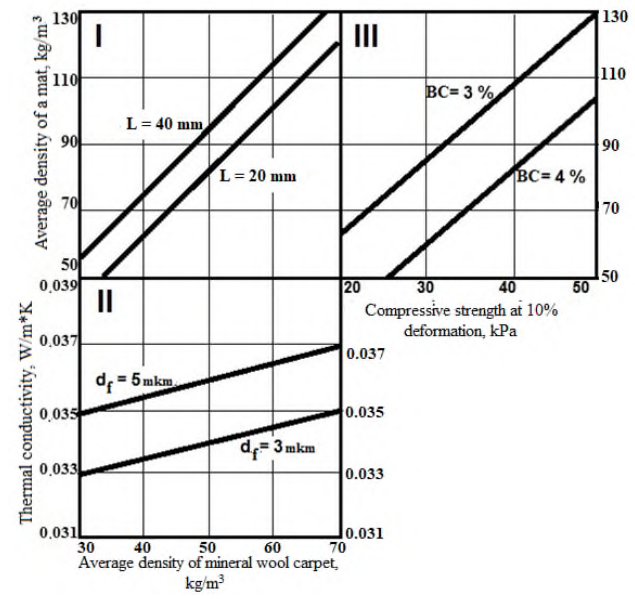

Fig. 1. The nomogram for selecting manufacturing parameters of mineral wool panels. The dependence of the compressive strength at $10 \%$ deformation, the average density and thermal conductivity of the mat from the average density of mineral wool carpet, compaction level (CL), the binder consumption $(\mathrm{BC})$, the diameter $(\mathrm{d})$ and length $(\mathrm{L})$ of fibers

Executed in MSUCE studiesshows that quite meet the requirements of thermal insulation products - panels based on modified mineral fiber. It is possible to manufacture as a structural insulation, as well as technical insulation, as well as systems which using such type of TIM. For process compartment and household premises used panel density of $80-100 \mathrm{~kg} / \mathrm{m} 3$ and a thermal conductivity of $0.040 \mathrm{~W} /(\mathrm{m} \cdot \mathrm{K})$. In shell material surface density $-100 \mathrm{~kg} / \mathrm{m} 2$. 
It deserves special attention to activities in this direction by the company ROCKWOOL. Experts of this company created a new type of mineral fiber the ROXUL with high alumina and low silicon content. Mineral wool basedon these fibers have high strength and temperature resistance. Biodegradable of this fiber is meets regulatory requirements.

System optimization of thermal insulation of pipelines implies several tasks: evaluation of the design parameters of the pipeline insulation and, in particular, the thickness of the insulation and method of mounting; select the way of how to insulate the pipeline: the type of insulation material, taking into account the technological features of its production; optimizing the cost of manufacturing this material.

Depending on the conditions of using the requirements for thermal insulation materials and system solutions are changing. In Cryotechnology preferred materials having closed porosity, extremely low thermal conductivity and are not destroyable at low temperatures close to absolute zero, the most well-proven products made from foamed glass or melt blown volcanic glasses. For most types of technical insulation is preferable to use products based on mineral wool, glass or basalt fiber. From basalt fiber is made, heat-insulating canvas, strands, panels and mats. From Mineral wool (stone or glass) is made Panels, mats and shaped products.

A special feature of these materials is the high open porosity, which implies their compulsory protection from the weather. Positive features are its low density and thermal conductivity, fire resistance, high flexibility and tight fit to the insulated surface. Fixing these materials is performed with help of special bandages or wire, with followed application of protective plaster, fixing special metal casings, laying (winding) roll materials: fiberglass, impregnated with a modified bitumen.

Cable heating pipes combined with its outer insulation is the most promising from the technological point of view, the method of maintaining the duty cycle of various production processes. The use of heating cables in the industry can provide the desired temperature and viscosity of the fluid passed through the pipes. Maintaining of optimal temperature conditions prevents the precipitation, an increase of viscosity, appearance of clots and reducing of fluid transfer rate through the pipe. This ensures the required process conditions and reduces the risk of potential material losses.

\section{Conclusion}

The calculation results are summarized in the nomogram (Fig. 1), allow us to conclude that the for heat transfer agent temperatures of $106-108^{\circ} \mathrm{C}$ the duration of the isothermal holding is insignificant (25-40 seconds) and the total duration of the heat treatment is regulated mainly by the time of drying and heating of mineral wool mat. Accordingly, providing appropriate blowing speed of heat transfer agent through the material, it is possible to reduce the heat treatment time is more than 2 times.

Basic and varying parameters of the heat treatment is determined by using the nomograms. This allows you to make a decision in the correction of process parameters, in particular in the transition to the new product types, correction of the raw material formulation and characteristics of the mineral fibers.

The developed method for the optimization of heat treatment of the mineral wool mat is based on the results of mathematical and statistical methods of planning. In addition to conventional methods, the method of analytical optimization, developed at the Department of NR MSUCE. Received analytical dependencies (and their graphical interpretation) allow for the development of algorithms for the management of production with the help of computers. A further direction of research is the dissemination of this method in the technology of other insulating materials. 
The pipeline insulation systems are using combined solutions: over a pipeline metal is placed heating cable (coiling with the calculated step), then fitted insulation (usually technical mineral wool mats) and all of it is protected by an external weather-resistant layer.

\section{References}

1. T. Holden, R. A. Schmidt, Commerce at light speed - an international comparative evaluation of CALS strategy and implementation in the USA and Japan, Industrial Management \& Data Systems, 101(1), 32- 40 (2001)

2. D. Tuchaev, E. Zarmanyan, E. Petrovskiy, A. Zemlyanko, K. Ivanov, A. Zhukov, Thermal insulation systems for the Arctic. FORM 2018 IOP Conf. Series: Materials Science and Engineering DOI: 10.1088/1757-899X/365/3/032015032041 (2018)

3. I. Gnip, S. Vaitkus, V. Kersulis, S. Vejelis, Long-term prediction of creep strains of mineral wool slabs under constant compressive stress. Mech Time Depend Mater, 16, 31-46 (2012) DOI 10. 1007/s11043-011-9152.

4. E. Arquis, C. Cicasu, Convectionphenomen in mineral wool in-stalled on vertical walls Proceedings of the International scientific-practical conference "Effective heat and sound insulating materials in modern construction and housing and communal services.", 18-21 (Moscow, Publishing house MSUCE, 2006)

5. A. Pilipenko, E. Bobrova, B. Efimov, Simulation of thermal treatment of mineral wool blanket, MATEC Web of Conferences, 18 November (ICMTMTE, 2019) 00091 DOI: https://doi.org/10.1051/matecconf/201929800091

6. B. M. Rumiantcev, A. D. Zhukov, D. B. Zelenshikov, A. S. Chkunin, K. K. Ivanov, Yu. $\mathrm{V}$. Sazonova, Insulation systems of the building construtions MATEC Web of Conferences, 86 (2016) DOI: http://dx.doi.org/10.1051/matecconf/ 20168604027

7. B. M. Rumiantcev, A. D. Zhukov, E. Yu. Bobrova, I. P. Romanova, D. B. Zelenshikov, T. V. Smirnova, The systems of insulation and a methodology for assessing the durability, MATEC Web of Conferences, 86 (2016) DOI: http://dx.doi.org/10.1051/matecconf/ 20168604036

8. S. Bergonnier, F. Hild, J.-B. Rieunier, S. Roux, Strain heterogeneities and local anisotropy in crimped glass wool, J. Mat. Science, 40, 5949-5954 (2005)

9. R. J. Good, M. K. Chauldhary, C. J. van Oss, Theory of adhesive forces across interfaces.2. Interfacial hydrogen bonds as acid base phenomena and as factors enhancing adhesion Fundamental of adhesion, 153-172 (New York: Plenum Press, 1991)

10. K. Ivanov, B. Efimov, Modeling of the structure and properties of a mineral wool cylinders MATEC Web of Conferences (ICMTMTE 2019) 18 November 2019, 00096 (2019) DOI: https://doi.org/10.1051/matecconf/201929800096

11. K. K. Ivanov, A. D. Zhukov, E. Yu. Bobrova, E. Yu. Zhukova, K. D. Vako, Thermal insulation shaped mineral wool products with effective binder E3S Web of Conferences, ISC SPbWOSCE-2018, 110, $02024 \quad$ (2019) DOI: https://doi.org/10.1051/e3sconf/201911002024

12. A. Medvedev, E. Bobrova, A. Poserenin, E. Zarmanyan, Evaluation of mineral fiber properties using $x$-ray fluorescence analysis and measurement of natural radioactivity 03018, 13 June (2018) DOI: https://doi.org/10.1051/matecconf/201817003018

13. K. P. Unnikrishnan, E. T. Thachil, Aging and thermal studies on epoxy resin modified by epoxidized novolacs. polymer-plastics technology and engineering, 45(4), 469-474 (2006) 
14. K. P. Unnikrishnan, E. T. Thachil, Effect of phenol/formaldehyde stoichiometry on the modification of epoxy resin using epoxidized novolacs. int. j. of pol. mat. 55(6), 385-398 (2006)

15. L. Min, Y. Chao, K. W. Shao, Z. G. Yi, K. Potter, Z. ZuoGuang, Evolution of the Wettability Between Carbon Fiber and Epoxy as a Function of Temperature and Resin Curing J. APPL. POLYM. SCI. (2013) DOI: 10.1002/APP.38634

16. R. H. E. Munn, Novel polyamide time epoxy curing agents J. Oil and Colour Chem. Assoc, 70(10), 300-304 (1987)

17. L. Min, Y. Chao, S. K. Wang, Y. Z. Gu, K. Potter, Z. ZuoGuang, Evolution of the Wettability Between Carbon Fiber and Epoxy as a Function of Temperature and Resin Curing J. APPL. POLYM. SCI. (2013) DOI: 10.1002/APP.38634

18. R. H. E. Munn, Novel polyamide time epoxy curing agents J. Oil and Colour Chem. Assoc. 70(10), 300-304 (1987)

19. A. Zhukov, E. Bobrova, A. Medvedev, N. Ushakov, D. Beniya, A. Poserenin, Modelling of Technology of Mineral Wool Products. International Scientific Conference Energy Management of Municipal Facilities and Sustainable Energy Technologies EMMFT 2018 Advances in Intelligent Systems and Computing, Springer, Cham, 983, 828-838 (2019)

20. Yu. L. Bobrov, Express method and laboratory equipment for quality evaluation of porous materials, Abstracts of the report of the international scientific-practical conference "Modern methods of quality control problems and their solutions", 43-44 (1985)

21. A. D. Zhukov, T. V. Konoval'tseva, E. Yu. Bobrova, E. A. Zinovieva, K. K. Ivanov, Thermal insulation: operational properties and methods of research. IPICSE, 14 December (2018) DOI: https://doi.org/10.1051/matecconf/201825101016

22. N. Martynov, et al. Journal of Physics: Conference Series 1614, 012060 (2020) doi:10.1088/1742-6596/1614/1/012060 